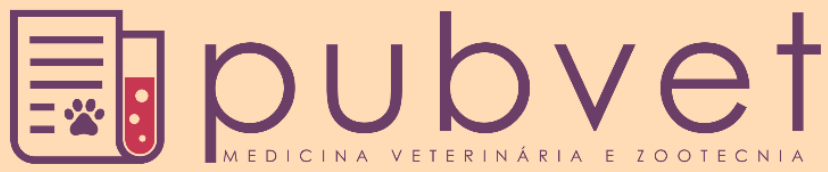

https://doi.org/10.31533/pubvet.v13n7a366.1-14

\section{Controle de temperatura: importância e influência na qualidade da carne bovina}

\author{
Ana Carolina Costa Borges ${ }^{1}$, Stefania Márcia de Oliveira Souza ${ }^{2} \bullet$ \\ ${ }^{1}$ Graduando em Medicina Veterinária, Centro universitário ICESP \\ ${ }^{2}$ Professora Dr. de Medicina Veterinária Centro universitário ICESP \\ *Autor para correspondência, E-mail: Borges.anavet@icloud.com
}

\begin{abstract}
Resumo. Objetivo: aspira se através desta pesquisa, avaliar condições de conservação e acondicionamento da carne bovina (patinho, músculo e paleta), refrigerada comercialmente, através da verificação de temperatura e a sua influência nas características organolépticas cor e aroma do alimento. É visado que, ao final deste, os resultados possam contribuir para nortear a apresentação de sugestões de melhorias para os problemas de conservação identificados. Métodos: As amostras de carne bovina foram colhidas aleatoriamente em estabelecimento comercial situado na Asa Norte, Brasília/DF. Para cada porção expostas na gôndola, foram aferidos a temperatura da superfície e centro da carne e verificado alterações de cor e odor do produto. Resultados: Demonstraram que o corte músculo, apresentou $60 \%$ das amostras fora dos padrões de temperatura (superfície e centro), mas não apresentou alteração de cor e aroma. O corte Paleta, 100\% das amostras apresentaram valores acima do permitido pela lei, sem alteração de aroma, mas com $60 \%$ das amostras com alteração na cor do produto. A temperatura de superfície do Patinho todas as amostras estavam alteradas e a temperatura do centro da carne $40 \%$ estavam acima do padrão. A cor e aroma não apresentaram alteração. Conclusões: Conclui-se que, apesar da verificação de alterações na temperatura da superfície e centro da carne, podem não ocorrer alterações na cor e aroma perceptíveis ao consumidor. Contudo, mesmo com estas variáveis normais, temperaturas acima do permitido podem propiciar desenvolvimento bacteriano causando danos a saúde do consumidor.
\end{abstract}

Palavras-Chave: Carne, bovino, temperatura, nutrientes

\section{Temperature control: importance and influence in the quality of bovine meat}

Abstract. Objective: The objective of this research was to evaluate the conditions of preservation and conditioning of commercially chilled beef (duck, muscle and palette) by means of the temperature verification and its influence on the organoleptic characteristics of the food. It is intended that, at the end of this one, the results can contribute to guide the presentation of suggestions for improvements to the conservation problems identified. Methods: The beef samples were randomly collected at a commercial establishment located in Asa Norte, Brasília / DF. For each portion exposed in the gondola, the temperature of the surface and center of the meat were checked and changes in color and odor of the product were verified. Results: They showed that the muscle cut, presented $60 \%$ of the samples outside the temperature patterns (surface and center), but did not present alteration of color and aroma. The Paleta cut, $100 \%$ of the samples presented values above that allowed by law, without alteration of aroma, but with $60 \%$ of the samples with alteration in color of the product. The surface temperature of the Duckling all samples were changed and the core temperature of the meat $40 \%$ were above standard. The color and 
aroma did not change. Conclusions: It is concluded that, despite changes in the temperature of the surface and the center of the meat, there can be no changes in the color and aroma perceivable to the consumer. However, even with these normal variables, temperatures above the allowed level can cause bacterial development causing damages to the health of the consumer.

Key words: Meat, bovine, temperature, nutrients

\section{Control de temperatura: importancia e influencia en la calidad de la carne bovina}

Resumen. Objetivo: Esta investigación tiene como objetivo evaluar las condiciones de conservación y empaque de la carne de bovina (patinho, músculo y paleta), refrigerada comercialmente a través de la verificación de la temperatura y su influencia en las características organolépticas, color y aroma de los alimentos. Se pretende que, al final de esto, los resultados puedan contribuir para guiar la presentación de sugerencias para mejorar los problemas de conservación identificados. Métodos: se tomaron muestras de carne al azar de un establecimiento comercial ubicado en Asa Norte, Brasilia / DF. Para cada porción expuesta en la góndola, se midieron la temperatura de la superficie y el centro de la carne y se verificaron los cambios en el color y el olor del producto. Resultados: demostraron que el corte músculo presentó el $60 \%$ de las muestras fuera de los estándares de temperatura (superficie y centro), pero no mostró cambios en el color y el aroma. En el corte Paleta, el $100 \%$ de las muestras presentaron valores superiores a los permitidos por la ley, sin alteración del aroma, pero con el $60 \%$ de las muestras con alteración en el color del producto. La temperatura superficial del corte patinho estaba alterada en todas las muestras y la temperatura de del centro de la carne $40 \%$ fue superior a la estándar. El color y el aroma no cambiaron. Conclusiones: Se puede concluir que, a pesar de los cambios en la temperatura de la superficie y del centro de la carne, pueden no producir cambios en el color y aroma perceptibles al consumidor. Sin embargo, incluso con estas variables normales, las temperaturas por encima del rango permitido pueden proporcionar un desarrollo bacteriano que cause daño a la salud del consumidor.

Palabra clave: Carne de res, bovino, temperatura, nutrientes

\section{Introdução}

O Brasil apresenta aceleração na economia influenciada pelo agronegócio. Este apresenta competitividade no mercado bovino, o que comprova ser uma atividade promissora, Osegura e rentável com resultados expressivos que são confirmados pelo aumento do consumo, melhorando a imagem do país diante do comércio internacional (Eiras et al., 2016; Guerrero et al., 2013a; Guerrero et al., 2018).

O rebanho comercial brasileiro em 2014 apresentou cerca de 213,3 milhões de cabeças de gado, mantendo-o em segundo lugar perdendo apenas para a Índia (ANUALPEC, 2018). O crescimento do comércio internacional de carne bovina tem sido extremamente expressivo nos últimos anos, onde o Brasil tem se destacado como um dos maiores exportador de carne bovina do mundo. Tendo assim, grande relevância como fornecedor de seus derivados para diversos países e, consequentemente, para uma infinidade de consumidores (FAPRI, 2019; Oliveira et al., 2013).

A demanda por alimentos de origem animal, advêm em função dos nutrientes provenientes desses produtos (Barcellos et al., 2010; Barcellos et al., 2017; Barcellos et al., 2019). Sua contribuição à dieta humana consiste na presença de proteínas, ácidos graxos essenciais, vitaminas do complexo B e sais minerais (Jiménez-Colmenero, 2007; Jiménez-Colmenero et al., 2012; Pereira \& Vicente, 2013). A preocupação com os aspectos relacionados à saúde e o bem-estar dos seres humanos tem aumentado de forma considerável. Os consumidores não estão apenas preocupados com os atributos como maciez e sabor, mas também com a forma de produção e obtenção da carne, e além da forma como o produto é exposto ao consumidor o que indica a qualidade do mesmo (Hocquette et al., 2001; Polkinghorne \& Thompson, 2010). 
A qualidade nutricional e sensoriais pode sofrer alterações por diversos tratamentos. $\mathrm{O}$ uso dos mecanismos tecnológicos e culinários, condições de conservação pelo frio artificial, pela salga, pela desidratação e os efeitos do modo de preparo culinário e industrial podem favorecer ou prejudicar o aspecto nutricional do produto (Guerrero et al., 2013a; Guerrero et al., 2013b; Monteschio et al., 2017; Passetti et al., 2019; Savell et al., 2005; Seyfert et al., 2004).

A temperatura de conservação da carne mantém suas características físicoquímicas. A diferenciação das carnes resfriadas dá-se pelas suas características peculiares e do seu prazo de vida comercial. Este prazo varia em função das condições de obtenção e das temperaturas em que são mantidas, devendo atingir a seu tempo máximo de duração quando obtidas em condições de higiene, procurando reduzir a contaminação inicial e manter condições de refrigeração para garantir a qualidade do produto e, consequentemente, trazer segurança alimentar para os consumidores (Devine et al., 2014; Rios-Mera et al., 2017; Van de Ven et al., 2014).

\section{Definição e caracterísiticas nutricionais da carne bovina}

A carne é o produto formado pelos tecidos musculares, conjuntivo, epitelial, ósseo e adiposo, além de outros órgãos que são considerados comestíveis como fígado, rins, o cérebro e outros tecidos (Menezes et al., 2010; Pascoal et al., 2010; Pascoal et al., 2009). A carne bovina é rica em nutrientes necessários para a vida dos seres humano. É utilizada como fonte protéica, ácidos graxos e aminoácidos essenciais, vitaminas do complexo B e minerais, além do zinco, ferro, fósforo e magnésio e as vitaminas que compõe os fatores nutricionais como: tiamina, riboflavina, niacina, B6 e B12 (Abdulkhaliq et al., 2007; Adams et al., 1982; Aizaki et al., 2011; Orellana et al., 2009). Os componentes presentes na carne explicam a sua perecibilidade, pois, favorecem o desenvolvimento de microrganismos responsáveis pela alteração do produto (Biesalski, 2002; Hocquette et al., 2005; Min \& Ahn, 2005). A composição média de nutrientes é de $21 \%$ de proteína, $70,5 \%$ de água, $6,0 \%$ de lipídios e $1,02 \%$ de cinza. Porém, o cozimento da carne permite perda de água, e outros componentes essenciais e seu consumo excessivo aumenta a composição calórica da dieta (Carvalho et al., 2017; Monteschio et al., 2019; Rivaroli et al., 2016; Strada et al., 2019).

\section{Aspectos da qualidade da carne}

Para a produção de carne de qualidade são necessários cuidados desde o nascimento do animal, até a obtenção do produto final, a fim de conservar os benefícios que o alimento pode oferecer ao consumidor (Guerrero et al., 2013b). A carne, quando em condições não adequadas, pode afetar diretamente a saúde do consumidor pelas infecções e intoxicações alimentares (Kozloski, 2011; Lehninger, 2006).

Esses aspectos são fundamentais quando são considerados como atributos de qualidade, questões como: tecnologia, relações nutricionais e sanitárias, ou seja, cor, textura, suculência, sabor, odor, maciez, $\mathrm{pH}$, capacidade de retenção de água, quantidade de gordura, perfil dos ácidos graxos, grau de oxidação, porcentagem de proteínas, vitaminas e minerais (Prado, 2010). Da mesma forma, a ausência de agentes contagiosos como tuberculose, encefalopatia espongiforme bovina, salmoneloses, além dos fatores residuais químicos e físicos como, antibióticos, hormônios, dioxina ou outras substâncias contaminantes. A preservação da qualidade da carne leva em consideração o bem estar do homem e do animal, além do meio ambiente, tendo com relevância a sustentabilidade, sem provocar poluição ambiental (Ferreira \& Matsubara, 1997; Germano \& Germano, 2003; Khor, 1997). Fatores que indicam a qualidade da carne para sua obtenção e consumo pelos consumidores podem ser percebidas, e esta percepção é resultado da interpretação das características dos produtos (Jiménez-Colmenero, 2000, 2007; Jiménez-Colmenero et al., 2012; Jiménez-Colmenero et al., 2006). Existem dois pontos perceptíveis sobre qualidade do produto: as características intrínsecas, ou seja, físicas, nutricionais, que não são observadas pelos consumidores. As características extrínsecas perceptíveis ao consumidor como, cheiro, sabor, maciez, quantidade de gordura e praticidade e higiênicas do produto interferem diretamente na decisão de adquirir o produto ou não (Guerrero et al., 2013a; Guerrero et al., 2013b).

A carne bovina, por suas particularidades, está sujeita a alterações por reações químicas, físicas e microbiológicas. Essas alterações podem ocorrer devido à degradação de proteínas e lipídeos, e podem ser causadas por agentes naturais, como o oxigênio, enzimas hidrolíticas presentes na carne e demais 
substâncias que são produzidas pela ação dos microrganismos (Frankel, 2005; Gray, 1978; Mercier et al., 2004; Morrissey et al., 1998).

Sua composição rica em nutrientes, umidade e pH favorável, além dos fatores externos como temperatura, condições higiênicas e atmosfera gasosa, propicia a contaminação microbiana desde a sangria até a comercialização, e geralmente está envolvida na disseminação de microrganismos que causam enfermidades. A qualidade dos produtos de origem animal é um aspecto fundamental para a saúde da população, porém, é uma consequência inevitável do processo que consiste em animais vivos que serão convertidos em carne para o consumo humano (Frankel, 2005; Gray, 1978; Mercier et al., 2004; Morrissey et al., 1998).

Os fatores que irão determinar a aceitabilidade da carne pelo consumidor estão relacionados com as condições higiênicas sanitárias e de conservação dos estabelecimentos processadores, manipuladores, distribuidores e comerciais, pois implicam diretamente em condições favoráveis para a multiplicação bacteriana deteriorante e patogênica que pode ocorrer pela má manipulação. Esses aspectos interferem nas características organolépticas devido à presença de proteases microbianas, qualidade nutricional e microbiológica da carne (Eiras et al., 2017; Guerrero et al., 2015; Guerrero et al., 2018; Guerrero et al., 2013b). Os parâmetros higiênicos sanitários são fundamentais para avaliação da qualidade microbiológica das carnes. São analisadas a higiene e limpeza durante o processamento, armazenamento, transporte e da provável vida útil da carne. Os alimentos derivados de animais estão susceptíveis à contaminação microbiana, pois, os próprios animais são contribuintes importantes para a multiplicação microbiana, tanto por patógenos como deteriorantes (Barcellos et al., 2010; Barcellos et al., 2017; Barcellos et al., 2019).

As características sensoriais da carne são características relacionadas com a coloração, odor e aroma. A coloração da carne é um dos primeiros aspectos observados pelo consumidor, e se dá devido às proteínas, hemoglobina (pigmento sanguíneo) e a mioglobina (pigmento muscular). A coloração adequada deve apresentar cor vermelho púrpura, devido principalmente à mioglobina (Boles \& Pegg, 2005; Jiménez-Colmenero, 2007; Mancini \& Hunt, 2005; Roça, 2001).

Quando ocorre a interação dessas proteínas com o oxigênio, resulta na coloração alterada da carne, a oximioglogina que dá coloração vermelha brilhante e a metamioglobina, que dá coloração marrom (Mancini \& Hunt, 2005). Ambas também influenciam na carne PSE (pálida, flácida e exsudativa) e DFD (escura, dura e seca) juntamente com as condições de abate do anima (Harris \& Shorthose, 1988; Lepetit \& Culioli, 1994). Pode ocorrer a descoloração bacteriana, surgindo pigmentos de cor verde, como a sulfomioglobina devido ao desenvolvimento de bactérias produtoras de $\mathrm{H}^{2} \mathrm{~S}$ (Pseudomonas mephitica) e a coleglobina em decorrência do crescimento de bactérias produtoras de $\mathrm{H}^{2} \mathrm{O}^{2}$ (Oliveira et al., 2013).

A cor da carne indica a concentração de mioglobina e seu estado de oxigenação ou oxidação na superfície do músculo. A característica aroma é um combinação de odor, sabor e $\mathrm{pH}$, podendo ser agrupados como saboroma. Estes são determinados por fatores antes do abate, como idade, espécie, raça, sexo, alimentação e manejo, outros como o pH final do músculo, condições de resfriamento e armazenamento também interferem nesta característica (Barcellos et al., 2017; Bernard et al., 2007; Bridi \& Silva, 2007; Guillemin et al., 2009).

\section{Conservação pelo frio}

A utilização de baixas temperaturas na conservação de alimentos é um método milenar, e para a indústria de alimentos representou um grande avanço, possibilitando o armazenamento e transporte de diversos produtos perecíveis; essa tecnologia garante a oferta de alimentos nutritiva e sensoriamente conservados por longo período (Souza et al., 2013). Segundo a portaria $n^{\circ}$ 304/96 do Ministério da Agricultura, a temperatura máxima para o transporte, o armazenamento e a comercialização de carnes bovinas, suínas e ovinas deve ser de até $7^{\circ} \mathrm{C}$. O tratamento pelo frio artificial ou industrial é a técnica mais empregada na conservação de carnes, pois é um alimento rico em nutrientes e possui elevada atividade de água, tornando-o susceptível à deterioração microbiana (Muela et al., 2010, 2012; Sañudo et al., 2013). Ainda segundo o autor Souza et al. (2013), o frio conserva o alimento pela inibição dos principais agentes causadores de alterações: atividade microbiológica, enzimática e metabólica dos tecidos animais após sacrifício. Uma das formas do uso do frio na conservação de alimentos é a 
refrigeração, nesse processo o alimento tem sua temperatura reduzida para valores entre -1 e $8^{\circ} \mathrm{C}$; e desse modo, é possível reduzir a velocidade das transformações microbiológicas e bioquímicas nos alimentos, prolongando assim a sua vida útil.

Quando ocorre contaminação microbiana na carne fresca, são encontrados diferentes tipos de microrganismos, influenciado pelas condições de abate e dentro dos estabelecimentos comerciais, pelas fontes de contaminação, como mesas de corte, facas, equipamentos e material fecal (Gill et al., 1998; Lindblad \& Berking, 2013; Nørrung \& Buncic, 2008).

A ausência do controle de temperatura pode provocar perda de lote em função da quebra na cadeia de frio, isso pode ocasionar alteração nas características organolépticas da carne, tornando-a impossível sua recuperação. Um forte influenciador na temperatura e tempo é a estocagem, pois, eles influenciam na qualidade e conservação do produto, cuja, a temperatura estiver acima de $7^{\circ} \mathrm{C}$ poderá levar a perda da qualidade (Neves Filho, 2009; Utrera et al., 2014; Ylä-Ajos \& Puolanne, 2007).

A carne resfriada atinge seu nível máximo de duração quando adquirida em melhores condições higiênicas e de técnicas onde foi reduzida ao máximo a contaminação inicial e então mantida em boas condições de refrigeração. As condições técnicas da aquisição do produto e a temperatura mantida irão afetar diretamente a duração do produto (López Osornio et al., 2008; Savell et al., 2005).

\section{Embalagens}

A embalagem tem como função proteger e armazenar o alimento das condições adversas, influenciando na durabilidade e qualidade da carne, pois minimizam reações de deterioração do produto, umidade, oxigenação de gordura e alterações nas características organolépticas como textura e aroma. A composição gasosa é a maior alteração que é causada pelo ambiente e que pode alterar os aspectos do produto, como a cor, tipo e o alcance da degradação microbiana e da sua oxidação (Carpenter et al., 2001; Ponnampalam et al., 2001; Realini \& Marcos, 2014; Vital et al., 2016). Diante disto, a permeabilidade dos materiais de embalagens ao oxigênio é um procedimento de grande valor quando associado à conservação de carnes resfriada (Polkinghorne et al., 2018; Sofos, 2014). Geralmente as embalagens utilizadas são de poliestireno envolto por filme de PVC esticáveis ou encolhíveis de alta permeabilidade ao oxigênio, pois podem manter a coloração vermelho brilhante na carne bovina, e protege o produto da desidratação superficial, estes minimizam a exsudação de líquidos, pelo forte contato da embalagem com o produto, melhorando a visão do consumidor e favorecendo a conservação, já que o mesmo promove disseminação da contaminação microbiológica (Fang et al., 2017; Gill et al., 1998).

A importância da refrigeração e da embalagem para a conservação da carne é fundamental, pois a manutenção da qualidade e a segurança da saúde do consumidor são fatores necessários para o estabelecimento e o consumo da carne bovina (Realini \& Marcos, 2014). Buscar se á, pelo projeto de pesquisa, avaliar condições de conservação e acondicionamento da carne bovina refrigerada; através da verificação de temperatura e a sua influência nas características organolépticas do alimento. É visado que, ao final deste, os resultados possam contribuir para nortear a apresentação de sugestões de melhorias para os problemas de conservação identificados.

\section{Métodos}

\section{Obtenção e análises dss amostras}

Foram analisadas três tipos de cortes diferentes de carnes bovinas, (A, B e C), onde de cada tipo de corte foi obtido cinco amostras aleatórias. Todas as carnes estavam embaladas em bandejas de poliestireno com filme de PVC expostas em gôndolas. As amostras foram obtidas e analisadas no mesmo dia, em estabelecimento comercial situado em Asa norte, Brasília- DF. Para cada amostra foi aferido à temperatura superficial e do centro da peça de carne por termômetro digital da marca (DELLT ${ }^{\circledR}$ ), além das características organolépticas cor e odor. Foi verificada a data de validade do produto e peso de cada amostra. A metodologia foi realizada seguindo o protocolo preconizado por Lima (2009).

Avaliação da temperatura, cor e odor 
Foi inserido termômetro digital da marca $\left(\right.$ DELLT $\left.^{\circledR}\right)$ nas amostras de carne que se encontravam nas gôndolas. A temperatura da superfície foi avaliada inserindo o termômetro entre o plástico e a peça da carne, já a temperatura do centro foi verificada inserindo o termômetro no tecido da peça de carne analisada. A cor foi avaliada por observação considerando-se normal as carnes que apresentaram coloração vermelho púrpura e anormal as que apresentaram coloração marrom e/ou vermelho brilhante. Já em relação ao odor as amostras consideradas normais devem apresentar odor característico de carne sendo considerados alterados odores pútridos, ou quaisquer odor não característico de carne bovina.

\section{Resultados e discussão}

A Portaria $n^{\circ}$ 304/96 determina que os estabelecimentos de abate de bovinos, bubalinos, suínos e aves, somente poderão ser distribuídos em cortes padronizados, devidamente embaladas e identificadas, à temperatura de até $7^{\circ} \mathrm{C}$. Os resultados estão apresentados na tabela 1.

Tabela 1. Resultados das análises de temperatura, aroma e cor dos cortes de carne (peso, temperatura, variação de carcterísticas, amostra, peça média, temperatura, sensoriais).

\begin{tabular}{llcccccc}
\hline \multirow{2}{*}{ Amostra } & \multirow{2}{*}{ Peça } & Peso, $\mathrm{kg}$ & \multicolumn{3}{c}{ Temperatura, ${ }^{\circ} \mathrm{C}$} & \multirow{2}{*}{ Aroma } & Cor \\
\cline { 3 - 6 } & & Superficie & Centro & Variação & & Própia \\
A1 & Músculo & 1,008 & 8,6 & 10,0 & 1,4 & Próprio & Alterada \\
A3 & Paleta & 1,228 & 9,7 & 8,6 & 1,1 & Próprio & Própia \\
\hline B1 & Patinho & 0,910 & 8,8 & 7,7 & 1,1 & Próprio & Própia \\
B2 & Músculo & 1,124 & 7,3 & 7,7 & 0,4 & Próprio & Alterada \\
B3 & Paleta & 1,030 & 14,0 & 15,0 & 1,0 & Próprio & Própia \\
C1 & Patinho & 0,700 & 8,0 & 7,0 & 1,0 & Próprio & Própia \\
C2 & Músculo & 1,044 & 5,6 & 5,0 & 0,6 & Próprio & Alterada \\
C3 & Paleta & 1,200 & 11,0 & 12,2 & 1,2 & Próprio & Própia \\
D1 & Patinho & 0,884 & 8,7 & 7,0 & 1,7 & Próprio & Própia \\
D2 & Músculo & 0,924 & 7,1 & 8,6 & 0,7 & Próprio & Própia \\
D3 & Paleta & 1,446 & 7,4 & 8,1 & 0,7 & Próprio & Própia \\
\hline E1 & Patinho & 0,770 & 9,6 & 8,5 & 1,1 & Próprio & Própia \\
E2 & Músculo & 0,962 & 6,1 & 6,0 & 0,1 & Próprio & Própia \\
E3 & Paleta & 1,644 & 8,6 & 9,2 & 0,6 & Próprio & Própia \\
\hline
\end{tabular}

De acordo com a tabela 1, em relação ao corte de carne músculo, avaliado quanto a temperatura de superfície e do centro da peça, as amostras $\left(\mathrm{A} 1: 8,6^{\circ} \mathrm{C} ; \mathrm{B} 1: 7,3^{\circ} \mathrm{C}\right.$ e $\left.\mathrm{D} 1: 7,1^{\circ} \mathrm{C}\right)$ e $\left(\mathrm{A} 1: 10,0^{\circ} \mathrm{C} ; \mathrm{B} 1: 7,7^{\circ} \mathrm{C}\right.$ e $\mathrm{D} 1: 8,6^{\circ} \mathrm{C}$ ) apresentaram valores acima do permitido pela legislação, representando $60 \%$ das amostras fora do valor padrão estabelecido para temperatura de conservação, porém não houve inconformidade quanto à cor e aroma das peças analisadas, como mostra a Figura 1.

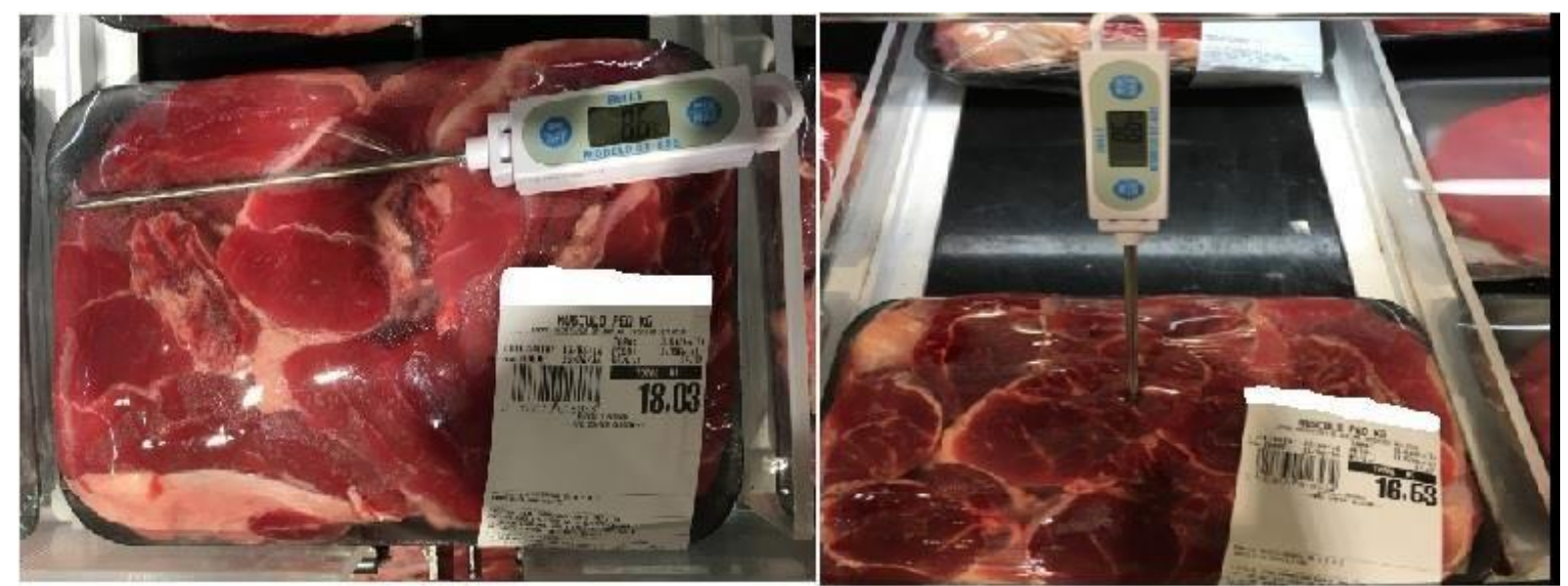

Figura 1. Corte de músculo com aferição da temperatura de superfície da carne/ centro da carne. Fonte: arquivo pessoal. 
Todas as amostras do corte paleta (A2, B2, C2, D2 e E2) apresentaram alteração de temperatura dos produtos analisados, tanto da superfície $\left(\mathrm{A} 2: 9,7^{\circ} \mathrm{C} ; \mathrm{B} 2: 14,0^{\circ} \mathrm{C} ; \mathrm{C} 2: 11,0^{\circ} \mathrm{C} ; \mathrm{D} 2: 7,4^{\circ} \mathrm{C}\right.$ e E2:8, $\left.6^{\circ} \mathrm{C}\right) ;$ como no centro da carne $\left(\mathrm{A} 2: 8,6^{\circ} \mathrm{C} ; \mathrm{B} 2: 15,0^{\circ} \mathrm{C} ; \mathrm{C} 2: 12,2^{\circ} \mathrm{C} ; \mathrm{D} 2: 8,1^{\circ} \mathrm{C}\right.$ e $\left.\mathrm{E} 2: 9,2^{\circ} \mathrm{C}\right)$. A característica aroma não houve alteração em nenhuma das amostras, já a característica cor, mostrou-se alterada em $60 \%$ das amostras (A2, B2 e C2) analisadas. A figura abaixo representa a imagem das respectivas amostras.

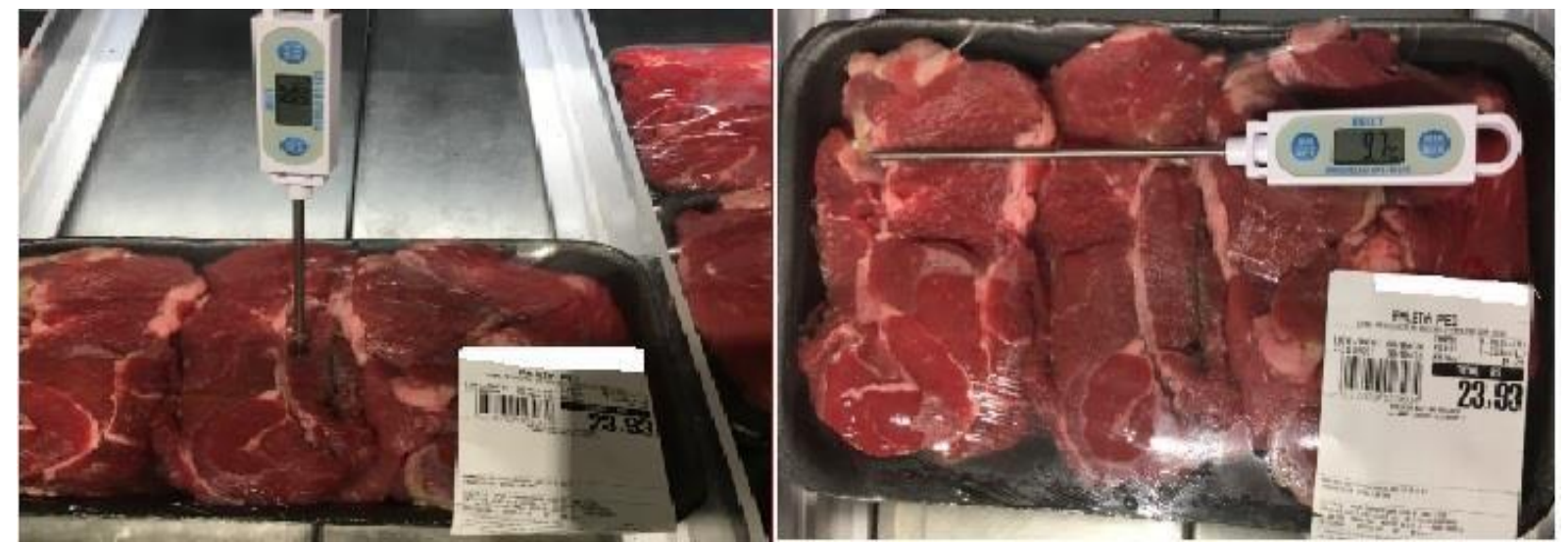

Figura 2. Corte de paleta com temperatura do centro e da superfície acima do padrão. Fonte: arquivo pessoal.

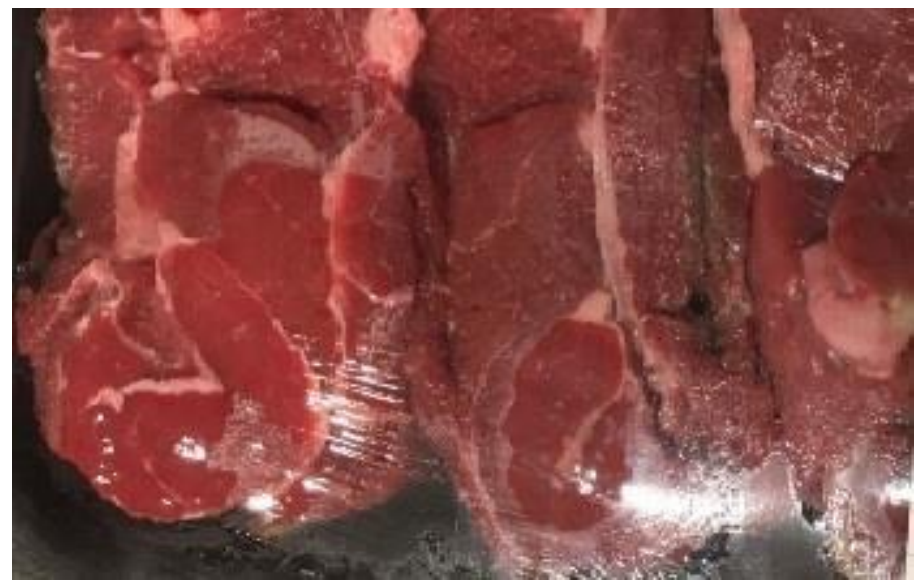

Figura 3. Corte de paleta com alteração da cor. Fonte: arquivo pessoal.

O corte patinho apresentou $20 \%$ de alteração na temperatura do centro $\left(\mathrm{A} 3: 7,7^{\circ} \mathrm{C}\right.$ e $\left.\mathrm{D} 3: 8,5^{\circ} \mathrm{C}\right)$ como demonstrado na figura 4A. Em relação à temperatura de superfície $100 \%\left(\mathrm{~A} 3: 8,8^{\circ} \mathrm{C} ; \mathrm{B} 3: 8,0^{\circ} \mathrm{C}\right.$; $\mathrm{C} 3: 8,7^{\circ} \mathrm{C} ; \mathrm{D} 3: 9,6^{\circ} \mathrm{C}$ e E3:8, $4^{\circ} \mathrm{C}$ ) apresentou alteração como demonstrado na figura 4B. Em relação às características aroma e cor não ocorreu alteração no produto analisado.
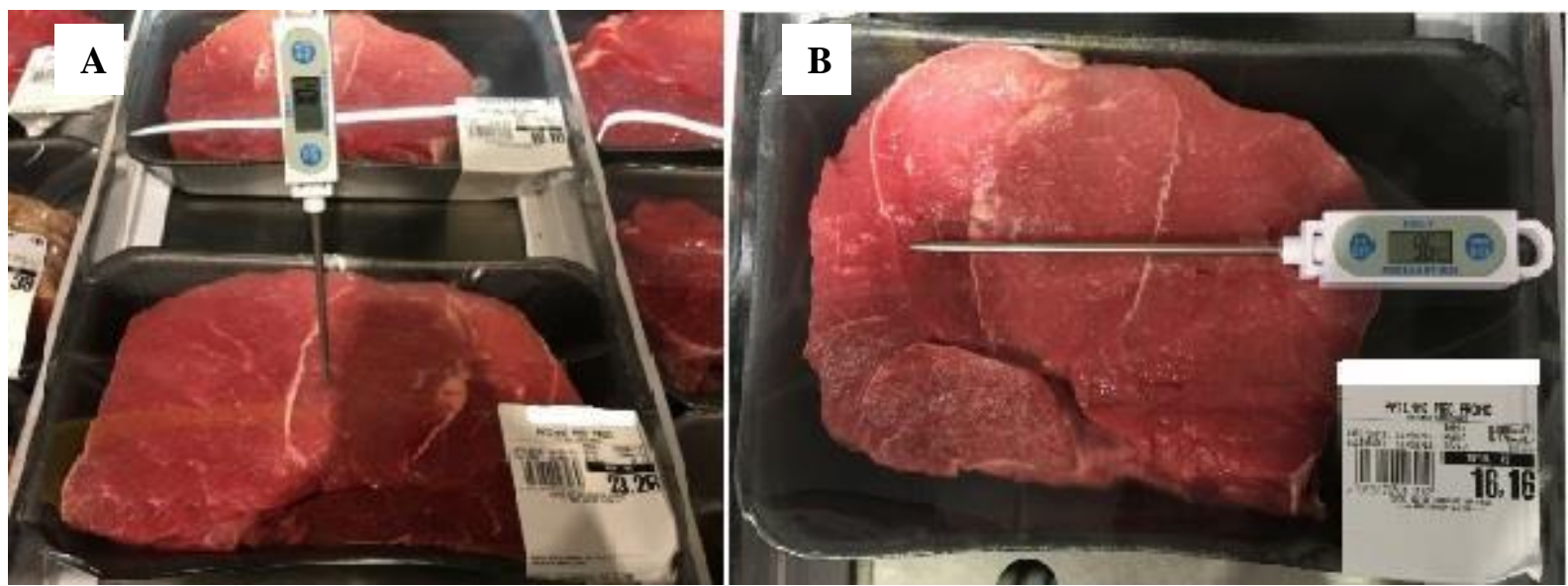

Figura 4. Corte de carne patinho com temperatura do centro (A) e da superfície (B). Fonte: arquivo pessoal. 
De acordo com as alterações observadas, as carnes analisadas apresentaram inconformidade com o parâmetro temperatura em quase $87 \%$ das peças em relação à temperatura na superfície, e $67 \%$ em relação à temperatura no centro. As temperaturas elevadas indicam que há deficiência no controle da temperatura das gôndolas de refrigeração, e/ou o termômetro utilizado no equipamento, apresentando mau funcionamento. Sabe-se que, a troca de calor com o ambiente das gôndolas, que são abertas, favorecem o aumento da temperatura das peças e a lotação de carnes nas gôndolas também propicia esse aumento, já que as embalagens de poliestireno são isolantes térmicos e dificultam o resfriamento para as demais peças.

Lima (2009) analisou temperatura de três tipos de cortes diferentes bife, patinho e acem avaliando aroma, cor e aspecto geral e identificou temperaturas elevadas (acima de $7^{\circ} \mathrm{C}$ ). Em relação às características organolépticas o autor relatou alterações somente na cor, o que de acordo com o mesmo, sugere não atender às exigências para a garantia da conservação do produto no prazo de 2 dias. Isto demonstra que, as alterações apresentadas nas amostras analisadas na presente pesquisa podem também ter ocorrido devido à falha no controle de temperatura dos equipamentos.

A coloração marrom apresentada nas amostras A2, B2 e C2 indica formação de metamioglobina nos cortes de carne. Existem três principais pigmentos, a mioglobina de cor púrpura, a oximioglobina de coloração vermelha brilhante (carne exposta ao oxigênio por pouco tempo), a metamioglobina de coloração marrom (carne exposta ao oxigênio por muito tempo) (Boles \& Pegg, 2005; Mancini \& Hunt, 2005). Esta alteração para cor marrom sugere que a matéria-prima pode ter sido exposta ao oxigênio por um período prolongado. Além disso, sugerem variações da temperatura para valores elevados, ou seja, a falta de manutenção dos equipamentos de refrigeração e termômetros dificultam a monitoração (Jiménez-Colmenero et al., 2012; Nychas et al., 2008), isso também de deve aos altos custos da climatização para armazenagem dos produtos (Souza et al., 2013). Diante do exposto, os resultados obtidos na presente pesquisa sugerem que estas amostras podem ter sido expostas excessivamente ao oxigênio levando a formação de metamioglobina e assim alterando a cor do produto.

De acordo com Gong et al. (2011); Lindblad \& Berking (2013); Tao \& Peng (2014), não só as baixas temperaturas são capazes de conservar as características, como cor e aroma, mas também as boas práticas de manipulação e fabricação. A exposição da carne a variadas condições ambiental (calor, acidez e agentes químicos) favorece a oxidação do ferro presentes nesses pigmentos, alterando a cor. Isto demonstra que não só a falha nos equipamentos de temperatura podem ter sido capazes de causar alteração nas amostras da pesquisa, na característica cor, mas também sugere que houve falha na manipulação.

As temperaturas identificadas acima de $10^{\circ} \mathrm{C}$ favorecem o desenvolvimento de microrganismos deteriorantes e patogênicos nos alimentos, como as Pseudomonas, os Estafilococos, os Micrococos, os Enterococos e os Coliformes (Li et al., 2013; Xavier et al., 2014). Assim, amostras mal acondicionada estão propícias há aumento do desenvolvimento bacteriano, o que pode causar danos à saúde do consumidor, enfatizando assim a importância do seu rigoroso controle. A característica sensoriais de odor não apresentou alteração em nenhuma das amostras analisadas.

Os bovinos quando submetidos a situações de estresse, como transporte, jejum prolongado, condições climáticas severas, e o comportamento sexual dos machos inteiros, podem resultar em rigor mortis atípico, com grandes prejuízos da qualidade da carne. Quando os animais são acometidos de estresse pré-abate, a reserva de glicogênio dos músculos desses animais pode ser parcialmente exaurida; resultando no estabelecimento do rigor mortis se dá na primeira hora, mesmo antes do processo de resfriamento. Isso ocorre porque a reserva energética não é suficiente para sustentar o metabolismo anaeróbio e produzir ácido lático capaz de fazer baixar o pH (Biesalski, 2005; Demars et al., 2007; Jiménez-Colmenero, 2007). Isto demonstra que caso o animal tenha sofrido estresse antes do abate e se a carne não for conservada em temperatura adequada pode levar a alterações no $\mathrm{pH}$ do produto final o que favorece alteração de odor e sabor do alimento.

A carne resultante desse processo de estresse terá $\mathrm{pH}>5,8$ (Tarrant \& Sherington, 1980), que proporciona às proteínas musculares uma alta capacidade de retenção de água, mas será escura, com vida de prateleira mais curta, que se dá porque na ausência de ácido lático e glicose livre as bactérias utilizam os aminoácidos da carne com produção de odores desagradáveis. Essa carne com pH alto 
também pode apresentar uma descoloração esverdeada, causada por bactérias que produzem $\mathrm{H}_{2} \mathrm{~S}$. Isto sugere que caso não seja feito controle de em relação a bem estar animal e a temperatura, irá favorecer desenvolvimento bacteriano o que pode levar a utilização de aminoácidos da carne e consequentemente surgimento de odores desagradáveis (Bernard et al., 2007; Geay et al., 2002; Harris \& Shorthose, 1988; Hocquette et al., 2001).

Diante do exposto, devem-se tomar medidas preventivas para a garantia da qualidade desses produtos, como a fiscalização rigorosa dos funcionários responsáveis pela monitoração dos equipamentos refrigeradores, bem como as boas práticas de manipulação desses alimentos e a mudança destes equipamentos abertos para equipamentos fechados, assim não possibilitaria a troca de calor com o ambiente e manteria a temperatura adequada dentro dos refrigeradores.

\section{Conclusão}

Conclui-se que o controle da temperatura é necessário dentro dos estabelecimentos comerciais para, a conservação das carnes expostas, pois diminui as contaminações e mantém a aparência agradável do produto para os consumidores. Caso este controle não seja realizado de forma adequada, mostrando-se acima da média exigida pela legislação dentro do prazo de validade, irá influenciar diretamente nas características de cor e aroma além de favorecer desenvolvimento de microrganismos e consequentemente prejudicando sua qualidade.

Diante do exposto, devem-se tomar medidas preventivas para a garantia da qualidade desses produtos, como a fiscalização rigorosa dos funcionários responsáveis pela monitoração dos equipamentos refrigeradores, bem como as boas práticas de manipulação desses alimentos e a mudança destes equipamentos abertos para equipamentos fechados, assim não possibilitaria a troca de calor com o ambiente e manteria a temperatura adequada dentro dos refrigeradores.

\section{Referêencias bibliográficas}

Abdulkhaliq, A. M., Meyer, H. H., Busboom, J. R. \& Thompson, J. M. (2007). Growth, carcass and cooked meat characteristics of lambs sired by Dorset rams heterozygous for the Callipyge gene and Suffolk and Texel rams. Small Ruminant Research, 71(1-3):92-97. doi: http://dx.doi.org/10.1016/j.smallrumres.2006.05.005

Adams, N. J., Smith, G. C. \& Carpenter, Z. L. (1982). Performance, carcass and palatability characteristics of Longhorn and other types of cattle. Meat Science, 7(1):67-79. doi: http://dx.doi.org/10.1016/0309-1740(82)90100-0

Aizaki, H., Sawada, M. \& Sato, K. (2011). Consumers' attitudes toward consumption of cloned beef. The impact of exposure to technological information about animal cloning. Appetite, 57(2):459-466. doi: http://dx.doi.org/10.1016/j.appet.2011.06.011

ANUALPEC. (2018). Anuário da Pecuária Brasileira (20th ed. Vol. 1). São Paulo, São Paulo, Brasil: Instituto FNP.

Barcellos, M. D., Kügler, J. O., Grunert, K. G., Van Wezemael, L., Pérez-Cueto, F. J. A., Ueland, Ø. \& Verbeke, W. (2010). European consumers' acceptance of beef processing technologies: A focus group study. Innovative Food Science \& Emerging Technologies, 11(4):721-732.

Barcellos, V. C., Mottin, C., Passetti, R. A. C., Guerrero, A., Valero, M. V., Eiras, C. E., . . Prado, I. N. (2017). Carcass characteristics and sensorial evaluation of meat from Nellore steers and crossbred Anus vs. Nellore bulls. Acta Scientiarum. Animal Sciences, 39(4):437-448. doi: http://dx.doi.prg/10.4025/actascianimsci.v39i4.36692.

Barcellos, V. C., Mottin, C., Prado, R. M., Schenkel, T., Viana, C. M. S., Vital, A. C. P., . . Prado, I. N. (2019). How the perception of quality for beef evaluated by the buyer at the time of purchase: Study in three Brazilian cities of different sizes - Curitiba, Campo Mourão and Palotina. Acta Scientiarum Animal.Sciences, 41(e46533):1-11. doi: http://dx.doi.org/10.4025/actascianimsci.v41i1.46533. 
Bernard, C., Cassar-Malek, I., Le Cunff, M., Dubroeucq, H., Renand, G. \& Hocquette, J. F. (2007). New indicators of beef sensory quality revealed by expression of specific genes. Journal of Agricultural and Food Chemistry, 55(13):5229-5237. doi: 10.1021/jf0633721

Biesalski, H. K. (2002). Meat and cancer: Meat as a component of a healthy diet. European Journal of Clinical Nutrition, 56(SUPPL. 1):S2-S11. doi: 10.1038/sj/ejen/1601347

Biesalski, H. K. (2005). Meat as a component of a healthy diet - Are there any risks or benefits if meat is avoided in the diet? Meat Science, 70(3 SPEC. ISS.):509-524. doi: 10.1016/j.meatsci.2004.07.017

Boles, J. A. \& Pegg, R. (2005). Meat color. Montana State University and Saskatchewan Food Product Innovation Program.

Bridi, A. M. \& Silva, C. A. (2007). Métodos de avaliação de carcaça e da carne suína. Londrina, Paraná, Brasil: Editora Midiograf.

Carpenter, C. E., Cornforth, D. P. \& Whittier, D. (2001). Consumer preferences for beef color and packaging did not affect eating satisfaction. Meat Science, 57(4):359-363.

Carvalho, C. B., Vital, A. C. P., Kempinski, E. M. B. C., Madrona, G. S., Reche, P. M., Guerrero, A., . . Prado, I. N. (2017). Quality and sensoria evaluation of beef hamburger made with herbs, spices, and reduced sodium content. Journal of Culinary Sciences \& Technology, 11-14. doi: http://www.tandfonline.com/loi/wcsc20.

Demars, J., Riquet, J., Sanchez, M. P., Billon, Y., Hocquette, J. F., Lebret, B., . . Gondret, F. (2007). Metabolic and histochemical characteristics of fat and muscle tissues in homozygous or heterozygous pigs for the body composition QTL located on chromosome 7. Physiological Genomics, 30(3):232241. doi: 10.1152/physiolgenomics.00270.2006

Devine, C., Wells, R., Lowe, T. \& Waller, J. (2014). Pre-rigor temperature and the relationship between lamb tenderisation, free water production, bound water and dry matter. Meat Science, 96(1):321-326. doi: http://dx.doi.org/10.1016/j.meatsci.2013.07.024

Eiras, C. E., Guerrero, A., Valero, M. V., Pardo, J. A., Ornaghi, M. G., Rivaroli, D. C., . . Prado, I. N. (2017). Effects of cottonseed hulls levels in the diet and aging time on visual and sensory meat acceptability from young bulls finished in feedlot. Animal, 11(3):529-537. doi: https://dx.doi.org/10.1017/S1751731116001749.

Eiras, C. E., Ornaghi, M. G., Valero, M. V., Rivaroli, D. C., Guerrero, A. \& Prado, I. N. (2016). How does the dietary cottonseed hull affect the carcass characteristics and meat quality of young bulls finished in a high-concentrate diet? Acta Scientiarum. Animal Sciences, 38(3):301-310. doi: http://dx.doi.org/10.4025/actascianimsci.v38i3.32149.

Fang, Z., Zhao, Y., Warner, R. D. \& Johnson, S. K. (2017). Active and intelligent packaging in meat industry. Trends in Food Science \& Technology, 6160-71.

FAPRI. (2019). Food and Agricultural Policy Research Institute. Food and Agricultural Policy Research Institute, from http://www.fapri.iastate.edu/tools/outlook.aspx

Ferreira, A. L. A. \& Matsubara, L. (1997). Radicais livres: conceitos, doenças relacionadas, sistema de defesa e estresse oxidativo. Revista da Associação Médica Brasileira, 43(1):61-68.

Frankel, E. N. (2005). Lipid oxidation: The Oily Press.

Geay, Y., Bauchart, D., Hocquette, J. F. \& Culioli, J. (2002). Nutritive value and sensorial qualities of ruminant meat. Valeur diététique et qualités sensorielles des viandes de ruminants. Incidence de l'alimentation des animaux, 15(1):37-52.

Germano, P. M. L. \& Germano, M. I. S. (2003). Higiene e vigilância sanitária de alimentos: qualidade das matérias-primas, doenças transmitidas por alimentos, treinamento de recursos humanos. São Paulo: Varela.

Gill, C. O., McGinnis, J. C. \& Bryant, J. (1998). Microbial contamination of meat during the skinning of beef carcass hindquarters at three slaughtering plants. International Journal of Food Microbiology, 42(3):175-184. doi: http://dx.doi.org/10.1016/S0168-1605(98)00074-9

Gong, S. L., Yang, Y. S., Shen, H., Wang, X. Y., Guo, H. P. \& Bai, L. (2011). Meat handling practices in households of Mainland China. Food Control, 22(5):749-755. doi: http://dx.doi.org/10.1016/j.foodcont.2010.11.009 
Gray, J. I. (1978). Measurement of lipid oxidation: a review. Journal of the American Oil Chemists' Society, 55(6):539-546.

Guerrero, A., Carvalho, C. B., Madrona, G. S., Cestari, L. A., Scapin, M. R. S. \& Prado, I. N. (2015). Envases alternativos biodegradables y activos con aceites esenciales para productos cárnicos. Eurocarne: La revista internacional del sector cárnico(238):45-52.

Guerrero, A., Prado, I. N. \& Valero, M. V. (2013a). Calidad de la carne de bovino de animales procedentes de sistemas intensivos, semi intensivos y pastoreo. Paper presented at the Simpósio de Produção Animal a Pasto, Londrina, Paraná.

Guerrero, A., Rivaroli, D. C., Sañudo, C., Campo, M. M., Valero, M. V., Jorge, A. M. \& Prado, I. N. (2018). Consumer acceptability of beef from two sexes supplemented with essential oil mix. Animal Production Science, 58(9):1700-1707. doi: http://dix.doi.org/10.1071/AN15306.

Guerrero, A., Valero, M. V., Campo, M. M. \& Sañudo, C. (2013b). Some factors that affect ruminant meat quality: from the farm to the fork. Review. Acta Scientiarum. Animal Sciences, 35(4):335-347.

Guillemin, N., Cassar-Malek, I., Hocquette, J. F., Jurie, C., Micol, D., Listrat, A., . . Picard, B. (2009). La maîtrise de la tendreté de la viande bovine : Identification de marqueurs biologiques. Inra Productions Animales, 22(4):331-344.

Harris, P. \& Shorthose, W. (1988). Meat texture. Developments in meat science, 4245-286.

Hocquette, J. F., Ortigues-Marty, I. \& Vermorel, M. (2001). Manipulation of tissue energy metabolism in meat-producing ruminants. Asian-Australasian Journal of Animal Sciences, 14(5):720-732.

Hocquette, J. F., Richardson, R. I., Prache, S., Medale, F., Duffy, G. \& Scollan, N. D. (2005). The future trends for research on quality and safety of animal products. Italian Journal of Animal Science, 4(SUPPL. 3):49-72.

Jiménez-Colmenero, F. (2000). Relevant factors in strategies for fat reduction in meat products. Trends in Food Science and Technology, 11(2):56-66. doi: 10.1016/S0924-2244(00)00042-X

Jiménez-Colmenero, F. (2007). Meat based functional foods. In Y. H. Hui (Ed.), Handbook of food production manufacturing (Vol. 1, pp. 989-1015). New Jersey: John Wiley \& Son Inc.

Jiménez-Colmenero, F., Herrero, A. M., Cofrades, S. \& Ruiz-Capillas, C. (2012). Meat and functional foods. In Y. H. Hui (Ed.), Handbook of meat and meat processing (Vol. 1, pp. 225-248). Boca Raton: CRC Press. Taylor Francis Group.

Jiménez-Colmenero, F., Reig, M. \& Toldrá, F. (2006). New approaches for the development of functional meat products. In L. M. I. Noller \& F. Toldrá (Eds.), Advanced technologies for meat processing (Vol. 1, pp. 275-308). London: Taylor \& Francis Group.

Khor, G. L. (1997). Nutrition and cardiovascular disease: an Asia Pacific perspective. Asian Pacific Journal Clinic Nutrition, 6122-142.

Kozloski, G. V. (2011). Bioquímica dos ruminantes (3a Ed. ed. Vol. 1). Santa Maria: Editora Universidade Federal de Santa Maria.

Lehninger, N. D. L. (2006). Principios de bioquímica. São Paulo.

Lepetit, J. \& Culioli, J. (1994). Mechanical properties of meat. Meat Science, 36(1-2):203-237. doi: 10.1016/0309-1740(94)90042-6

Li, X., Babol, J., Wallby, A. \& Lundström, K. (2013). Meat quality, microbiological status and consumer preference of beef gluteus medius aged in a dry ageing bag or vacuum. Meat Science, 95(2):229-234. doi: http://dx.doi.org/10.1016/j.meatsci.2013.05.009.

Lima, M. B. Conservação de Carne Bovina Resfriada Exposta à Venda em Supermercados daCidade do Recife, 2009. 29f. Monografia apresentada como exigência final para obtenção do título de (Especialista) em Gestão da Qualidade e Vigilância Sanitária em Alimentos à Universidade Federal Rural do Semi-Árido (UFERSA), Recife-PE, 2009.

Lindblad, M. \& Berking, C. (2013). A meat control system achieving significant reduction of visible faecal and ingesta contamination of cattle, lamb and swine carcasses at Swedish slaughterhouses. Food Control, 30(1):101-105. doi: http://dx.doi.org/10.1016/j.foodcont.2012.07.040 
López Osornio, M. M., Hough, G., Salvador, A., Chambers Iv, E., McGraw, S. \& Fiszman, S. (2008). Beef's optimum internal cooking temperature as seen by consumers from different countries using survival analysis statistics. Food Quality and Preference, 19(1):12-20. doi: http://dx.doi.org/10.1016/j.foodqual.2007.06.004

Mancini, R. A. \& Hunt, M. C. (2005). Current research in meat color. Meat Science, 71(1):100-121. doi: http://dx.doi.org/10.1016/j.meatsci.2005.03.003.

Menezes, L. F. G., Restle, J., Brondani, I. L., Silveira, M. F., Freitas, L. S. \& Pizzuti, L. Â. D. (2010). Características da carcaça e da carne de novilhos superjovens da raça Devon terminados em diferentes sistemas de alimentação. Revista Brasileira de Zootecnia, 39(3):667-676.

Mercier, Y., Gatellier, P. \& Renerre, M. (2004). Lipid and protein oxidation in vitro, and antioxidant potential in meat from Charolais cows finished on pasture or mixed diet. Meat Science, 66(2):467473. doi: 10.1016/s0309-1740(03)00135-9

Min, B. \& Ahn, D. U. (2005). Mechanism of lipid peroxidation in meat and meat products-A review. Food Science and Biotechnology, 14(1):152-163.

Monteschio, J. O., Souza, K. A., Vital, A. C. P., Guerrero, A., Valero, M. V., Kempinski, E. M. B. C., . .. Prado, I. N. (2017). Clove and rosemary essential oils and encapsuled active principles (eugenol, thymol and vanillin blend) on meat quality of feedlot-finished heifers. Meat Science, 13050-57. doi: http://dx.doi.org/10.1016/j.meatsci.2017.04.002.

Monteschio, J. O., Vargas-Junior, F. M., Almeida, F. L. A., Pinto, L., Kaneko, I. N., Almeida, A. A., . . . Prado, I. N. (2019). The effect of encapsulated active principles (eugenol, thymol and vanillin) and clove and rosemary essential oils on the structure, collagen content, chemical composition and fatty acid profile of Nellore heifers muscle. Meat Science, 15527-35. doi: https://doi.org/10.1016/j.meatsci.2019.04.019.

Morrissey, P. A., Sheehy, P. J. A., Galvin, K., Kerry, J. P. \& Buckley, D. J. (1998). Lipid stability in meat and meat products. Meat Science, 49, Supplement 1(0):S73-S86. doi: http://dx.doi.org/10.1016/S0309-1740(98)90039-0

Muela, E., Sañudo, C., Campo, M. M., Medel, I. \& Beltrán, J. A. (2010). Effect of freezing method and frozen storage duration on instrumental quality of lamb throughout display. Meat Science, 84(4):662669. doi: http://dx.doi.org/10.1016/j.meatsci.2009.10.028.

Muela, E., Sañudo, C., Campo, M. M., Medel, I. \& Beltrán, J. A. (2012). Effect of freezing method and frozen storage duration on lamb sensory quality. [doi: 10.1016/j.meatsci.2011.07.003]. Meat Science, 90(1):209-215.

Neves Filho, L. C. (2009). Refrigeração: uma cultura de respeito ao cliente, parceiro e produto. Revista Nacional da Carne, 33(384):74-86.

Nørrung, B. \& Buncic, S. (2008). Microbial safety of meat in the European Union. Meat Science, 78(12):14-24. doi: http://dx.doi.org/10.1016/j.meatsci.2007.07.032

Nychas, G.-J. E., Skandamis, P. N., Tassou, C. C. \& Koutsoumanis, K. P. (2008). Meat spoilage during distribution. Meat Science, 78(1-2):77-89. doi: http://dx.doi.org/10.1016/j.meatsci.2007.06.020

Oliveira, J. D., Silva, T. R. S. \& Correia, M. G. S. (2013). Fatores determinantes da qualidade nutricional da carne bovina. Caderno de Graduação-Ciências Biológicas e da Saúde-UNIT, 1(2):37-46.

Orellana, C., Peña, F., García, A., Perea, J., Martos, J., Domenech, V. \& Acero, R. (2009). Carcass characteristics, fatty acid composition, and meat quality of Criollo Argentino and Braford steers raised on forage in a semi-tropical region of Argentina. Meat Science, 81(1):57-64. doi: http://dx.doi.org/10.1016/j.meatsci.2008.06.015.

Pascoal, L. L., Lobato, J. F. P., Restle, J., Vaz, F. N., Vaz, R. Z. \& Menezes, L. F. G. (2010). Beef cuts yield of steer carcasses graded according to conformation and weight. Revista Brasileira de Zootecnia, 39(6):1363-1371.

Pascoal, L. L., Piva Lobato, J. F., Restle, J., Vaz, R. Z. \& Vaz, F. N. (2009). Meat yield of culled cow and steer carcasses. Revista Brasileira de Zootecnia, 38(11):2230-2237. doi: 10.1590/S151635982009001100024 
Passetti, R. A. C., Prado, I. N., Macedo, F. A. F., Teixeira, A. J. C., Cardoso, C. A. L., Santos, G. R. A. $\&$ Santos, C. A. (2019). Physicochemical characteristics of dry aged beef from younger Nellore bulls slaughtered at different boy weights. Tropical Animal Health and Production, 51(263):1-6. doi: http://dx.doi.org/10.1007/s11250-019-01944-9.

Pereira, P. M. C. C. \& Vicente, A. F. R. B. (2013). Meat nutritional composition and nutritive role in the human diet. Meat Science, 93(3):586-592. doi: http://dx.doi.org/10.1016/j.meatsci.2012.09.018

Polkinghorne, R. J., Philpott, J., Perovic, J., Lau, J., Davies, L., Mudannayake, W., . . Thompson, J. M. (2018). The effect of packaging on consumer eating quality of beef. Meat Science, 14259-64.

Polkinghorne, R. J. \& Thompson, J. M. (2010). Meat standards and grading: A world view. Meat Science, 86(1):227-235. doi: http://dx.doi.org/10.1016/j.meatsci.2010.05.010

Ponnampalam, E. N., Trout, G. R., Sinclair, A. J., Egan, A. R. \& Leury, B. J. (2001). Comparison of the color stability and lipid oxidative stability of fresh and vacuum packaged lamb muscle containing elevated omega-3 and omega-6 fatty acid levels from dietary manipulation. Meat Science, 58(2):151161.

Prado, I. N. (2010). Produção de bovinos de corte e qualidade da carne (Vol. 1). Maringá, Paraná, Brasil: Eduem.

Realini, C. E. \& Marcos, B. (2014). Active and intelligent packaging systems for a modern society. Meat Science, 98(3):404-419. doi: http://dx.doi.org/10.1016/j.meatsci.2014.06.031.

Rios-Mera, J. D., Pinto, J. S. S. \& Contreras-Castillo, C. J. (2017). Effect of ultimate pH and ageing on thermal denaturation of bovine muscle proteins. Meat Science, 13125-27. doi: https://doi.org/10.1016/j.meatsci.2017.04.017

Rivaroli, D. C., Guerrero, A., Valero, M. M., Zawadzki, F., Eiras, C. E., Campo, M. M., . . Prado, I. N. (2016). Effect of essential oils on meat and fat qualities of crossbred young bulls finished in feedlots. Meat Science, 121278-284. doi: http://dx.doi.org/10.1016/j.meatsci.2016.06.017.

Roça, R. O. (2001). Abate humanitário de bovinos. Revista de Educação Continuada em Medicina Veterinária e Zootecnia do CRMV-SP, 4(2):73-85.

Sañudo, C., Muela, E. \& Campo, M. M. (2013). Key factors involved in lamb quality from farm to fork in europe. Journal of Integrative Agriculture, 12(11):1919-1930. doi: http://dx.doi.org/10.1016/S2095-3119(13)60629-2

Savell, J. W., Mueller, S. L. \& Baird, B. E. (2005). The chilling of carcasses. Meat Science, 70(3):449459. doi: http://dx.doi.org/10.1016/j.meatsci.2004.06.027

Seyfert, M., Hunt, M., Mancini, R., Hachmeister, K., Kropf, D. \& Unruh, J. (2004). Accelerated chilling and modified atmosphere packaging affect colour and colour stability of injection-enhanced beef round muscles. Meat Science, 68(2):209-219.

Sofos, J. N. (2014). Chapter 6 - Meat and Meat Products. In Y. Motarjemi \& H. Lelieveld (Eds.), Food Safety Management (pp. 119-162). San Diego: Academic Press.

Souza, M. C., Teixeira, L. Q., Rocha, C. T., Ferreira, G. A. M. \& Lima Filho, T. (2013). Emprego do frio na conservação de alimentos. Enciclopédia Biosfera, 9(16):1028-1046.

Strada, E. S. O., Silva, R. R., Carvalho, G. G. P., Barbosa, L. P., Prado, I. N., Araújo, F. L., . . Lima Júnior, D. M. (2019). Fatty acid composition of beef cattle finished on tropical pasture and supplemented with crude glycerin. Semina: Ciências Agrárias, 40(2):993-1000. doi: http://dx.doi.org/10.5433/1679-0359.2019v40n2p993.

Tao, F. \& Peng, Y. (2014). A method for nondestructive prediction of pork meat quality and safety attributes by hyperspectral imaging technique. Journal of Food Engineering, 12698-106. doi: http://dx.doi.org/10.1016/j.jfoodeng.2013.11.006

Tarrant, P. V. \& Sherington, J. (1980). An investigation of ultimate $\mathrm{pH}$ in the muscles of commercial beef carcasses. Meat Science, 4(4):287-297. doi: http://dx.doi.org/10.1016/0309-1740(80)90028-5

Utrera, M., Morcuende, D. \& Estévez, M. (2014). Temperature of frozen storage affects the nature and consequences of protein oxidation in beef patties. Meat Science, 96(3):1250-1257. 
Van de Ven, R. J., Pearce, K. L. \& Hopkins, D. L. (2014). Post-mortem modelling of pH and temperature in related lamb carcases. Meat Science(96):1034-1039. doi: 10.1016/j.meatsci.2012.10.001.

Vital, A. C. P., Guerrero, A., Monteschio, J. O., Valero, M. V., Carvalho, C. B., Abreu Filho, B. A., . . . Prado, I. N. (2016). Effect of edible and active coating (with rosemary and oregano essential oils) on beef characteristics and consumer acceptability. PlosOne, 1(1):1-15. doi: http://dx.doi.org/10.1016/0168-1591(86)90115-2.

Xavier, C., Gonzales-Barron, U., Paula, V., Estevinho, L. \& Cadavez, V. (2014). Meta-analysis of the incidence of foodborne pathogens in Portuguese meats and their products. Food Research International, 55311-323. doi: http://dx.doi.org/10.1016/j.foodres.2013.11.024.

Ylä-Ajos, M. \& Puolanne, E. (2007). Temperature shows greater impact on bovine Longissimus dorsi muscle glycogen debranching enzyme activity than does salt concentration. Meat Science, 77(4):587592. doi: http://dx.doi.org/10.1016/j.meatsci.2007.05.009.

Recebido: 24 de maio, 2019.

Aprovado: 25 de junho, 2019.

Publicado: 29 de julho, 2019.

Licenciamento: Este artigo é publicado na modalidade Acesso Aberto sob a licença Creative Commons Atribuição 4.0 (CC-BY 4.0), a qual permite uso irrestrito, distribuição, reprodução em qualquer meio, desde que o autor e a fonte sejam devidamente creditados. 